\title{
Side-to-side portal vein reconstruction for infant-to-infant deceased donor whole liver transplantation: Report of 2 cases with video
}

\author{
Jung-Man Namgoong, Shin Hwang, Chul-Soo Ahn, Dong-Hwan Jung, and Gil-Chun Park
}

Department of Surgery, Asan Medical Center, University of Ulsan College of Medicine, Seoul, Korea

\begin{abstract}
Infant-to-infant whole liver transplantation (I2I-WLT) has been rarely performed in Korea. Unlike living donor liver transplantation or split liver transplantation, the donor graft portal vein (PV) in I2I-WLT is very small in diameter, so risk of PV complications increases significantly. We present two cases of I2I-WLT with application of side-to-side unification venoplasty for secure PV reconstruction. The first case recipient was a 10-month-old female baby who weighed 6.0 $\mathrm{kg}$. She was diagnosed with progressive familial intrahepatic cholestasis. The deceased donor was a 12-month-old boy. The graft weight was $245 \mathrm{~g}$, so the graft-recipient weight ratio (GRWR) was $4.1 \%$. PV was reconstructed using side-to-side unification venoplasty. The function of graft liver recovered uneventfully and there was no evidence of PV complications. She is currently doing well for 4 years. The second case recipient was a 10-month-old female baby who weighed $8.8 \mathrm{~kg}$. She had also undergone Kasai operation for biliary atresia. GRWR was $6.0 \%$. Because the graft liver was much larger than the native liver, we designed the length of the extrahepatic PV more redundant than the precedent cases to avoid extrinsic compression by the large-sized caudate lobe. The PV was reconstructed using side-to-side unification venoplasty. The function of the graft liver recovered uneventfully. There was no evidence of PV complications. She is currently doing well for 2 years. As the PV size in infant donors and recipients is very small, PV reconstruction in I2I-WLT requires specialized surgical techniques of side-to-side unification venoplasty. Three supplementary video clips are provided. (Ann Hepatobiliary Pancreat Surg 2020;24:301-304)
\end{abstract}

Key Words: Complication; Portal vein; Pediatric transplantation; Deceased donor; Venoplasty

\section{INTRODUCTION}

Infant donors younger than 12 months old or with a body weight less than $10 \mathrm{~kg}$ can provide very small-sized solid organs. Considering graft-to-recipient size matching, the whole liver grafts from such infant deceased donors are the most suitable for infant recipients. The infant-toinfant whole liver transplantation (I2I-WLT) procedure has been rarely performed in Korea because of the extremely low incidence of infant deceased donors. Infant recipients with biliary atresia often exhibit portal vein (PV) hypoplasia with underdevelopment of the splanchnic blood flow system, and several innovative surgical techniques have been developed to prevent anastomotic stenosis of the PV. ${ }^{1-4}$ Unlike living donor liver transplantation (LDLT) or split liver transplantation, the donor graft PV in I2I-WLT is very small in diameter, so the risk of PV complications increases significantly. We herein present two cases of I2I-WLT with application of side-to-side unification venoplasty for secure PV reconstruction.

\section{DEVELOPMENT OF SIDE-TO-SIDE UNIFICATION VENOPLASTY TECHNIQUE}

For secure PV reconstruction, the effective size of the anastomotic cross-sectional area and a streamlined configuration without axial rotation are the essentially important parameters. To satisfy these parameters, side-to-side unification venoplasty technique was developed as follows: A deep longitudinal incision was made in the " 6 o'clock" direction of the graft PV and the "12 o'clock" direction of the recipient PV; then, continuous sutures were used to unify these two PVs, which generated an enlarged con-

Received: June 7, 2020; Revised: June 8, 2020; Accepted: June 9, 2020

Corresponding author: Shin Hwang

Department of Surgery, Asan Medical Center, University of Ulsan College of Medicine, 88 Olympic-ro 43-gil, Songpa-gu, Seoul 05505, Korea Tel: +82-2-3010-3930, Fax: +82-2-3010-6701, E-mail: shwang@amc.seoul.kr

Copyright (C) 2020 by The Korean Association of Hepato-Biliary-Pancreatic Surgery

This is an Open Access article distributed under the terms of the Creative Commons Attribution Non-Commercial License (http://creativecommons.org/ licenses/by-nc/4.0) which permits unrestricted non-commercial use, distribution, and reproduction in any medium, provided the original work is properly cited. Annals of Hepato-Biliary-Pancreatic Surgery • pISSN: 2508-5778 - elSSN: 2508-5859 
duit from the superior mesenteric vein-splenic vein confluence to the graft hilar PV confluence (Fig. 1).

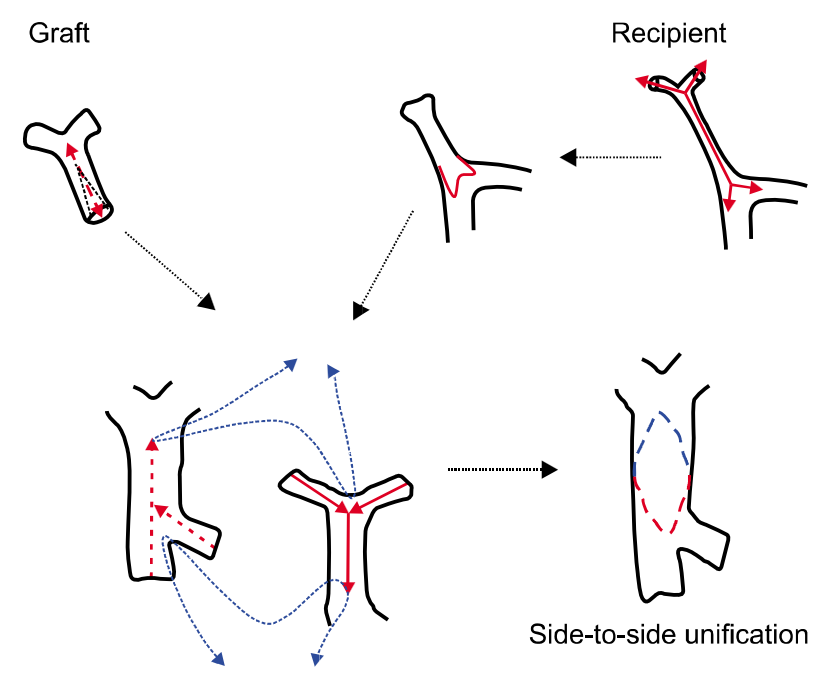

Fig. 1. Illustration of the side-to-side unification technique used for portal vein (PV) reconstruction. A deep longitudinal incision was made at the "6 o'clock" direction of the graft PV and the "12 o'clock" direction of the recipient PV. Running sutures were then used to unify these two PVs. This technique creates an enlarged conduit from the superior mesenteric vein-splenic vein confluence to the hilar PV confluence.

\section{CASE PRESENTATION}

\section{Case 1}

The recipient was a 10-month-old female baby who weighed $6.0 \mathrm{~kg}$. She was diagnosed with progressive familial intrahepatic cholestasis. The deceased donor was a 12-month-old boy (Supplementary Video 1). The graft weight was $245 \mathrm{~g}$, so the graft-recipient weight ratio (GRWR) was 4.1\%. Modified piggyback method was used for inferior vena cava anastomosis. The PV was reconstructed using above-mentioned side-to-side unification venoplasty (Fig. 2, Supplementary Video 2). This was the first case who was benefited from our technical innovation on PV reconstruction. One hepatic artery was reconstructed under surgical microscopy. Roux-en-Y hepaticojejunostomy was performed. The function of graft liver recovered uneventfully and there was no evidence of PV complications. She is currently doing well for 4 years.

\section{Case 2}

The recipient was a 10-month-old female baby who weighed $8.8 \mathrm{~kg}$. She had undergone a Kasai operation for biliary atresia. The deceased donor was a 10-month-old boy. The graft weight was $525 \mathrm{~g}$, so the GRWR was $6.0 \%$. Modified piggyback method was used for IVC
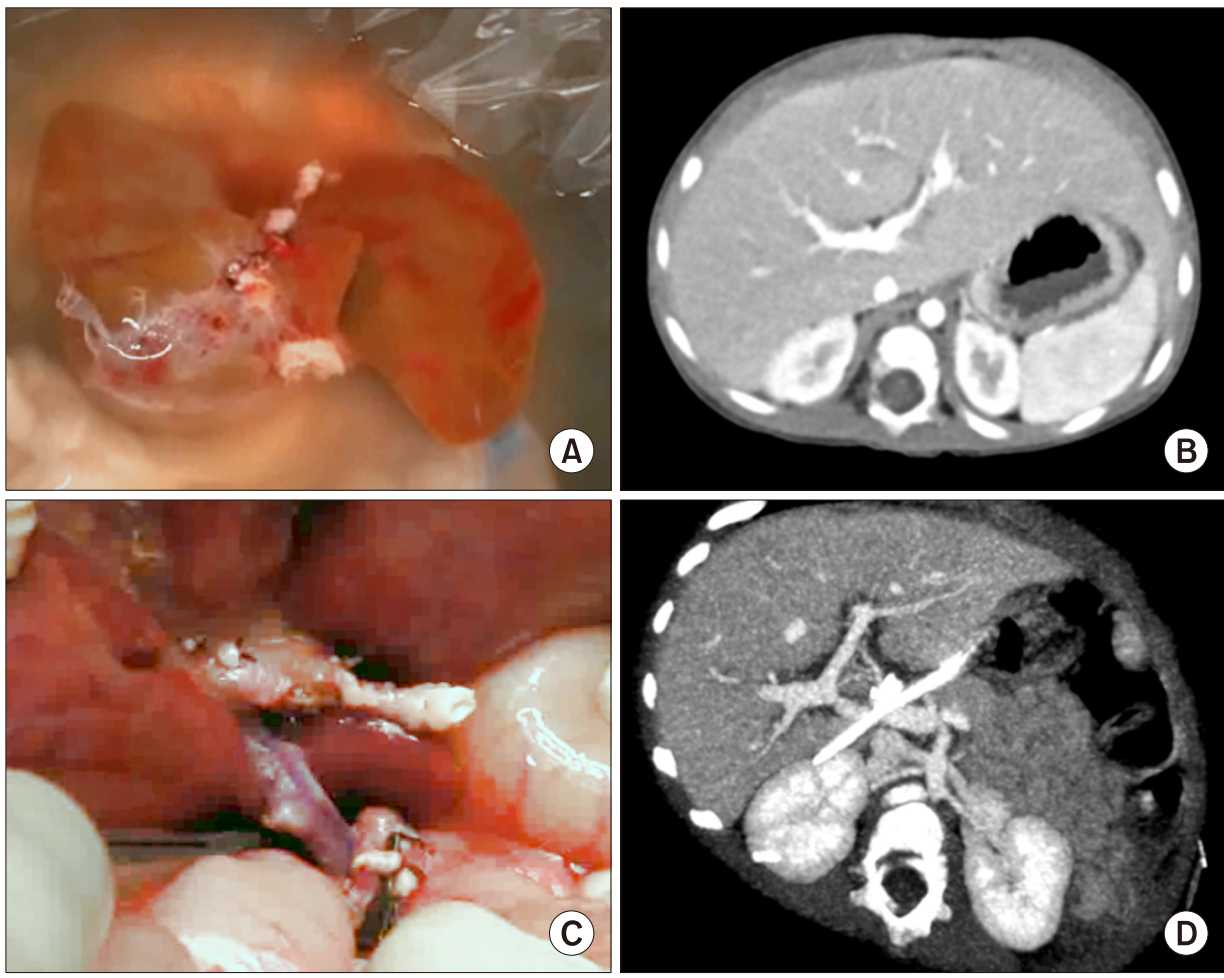

Fig. 2. Imaging findings of $P V$ reconstruction using the side-toside unification technique in the Case 1. The ventral surface of the whole liver graft was visible (A). A pretransplant computed tomography (CT) shows recipient's portal vein anatomy (B). An intraoperative photograph shows completed PV reconstruction just after portal reperfusion (C). CT scan taken at posttransplant day 7 shows no evidence of PV complication (D). 

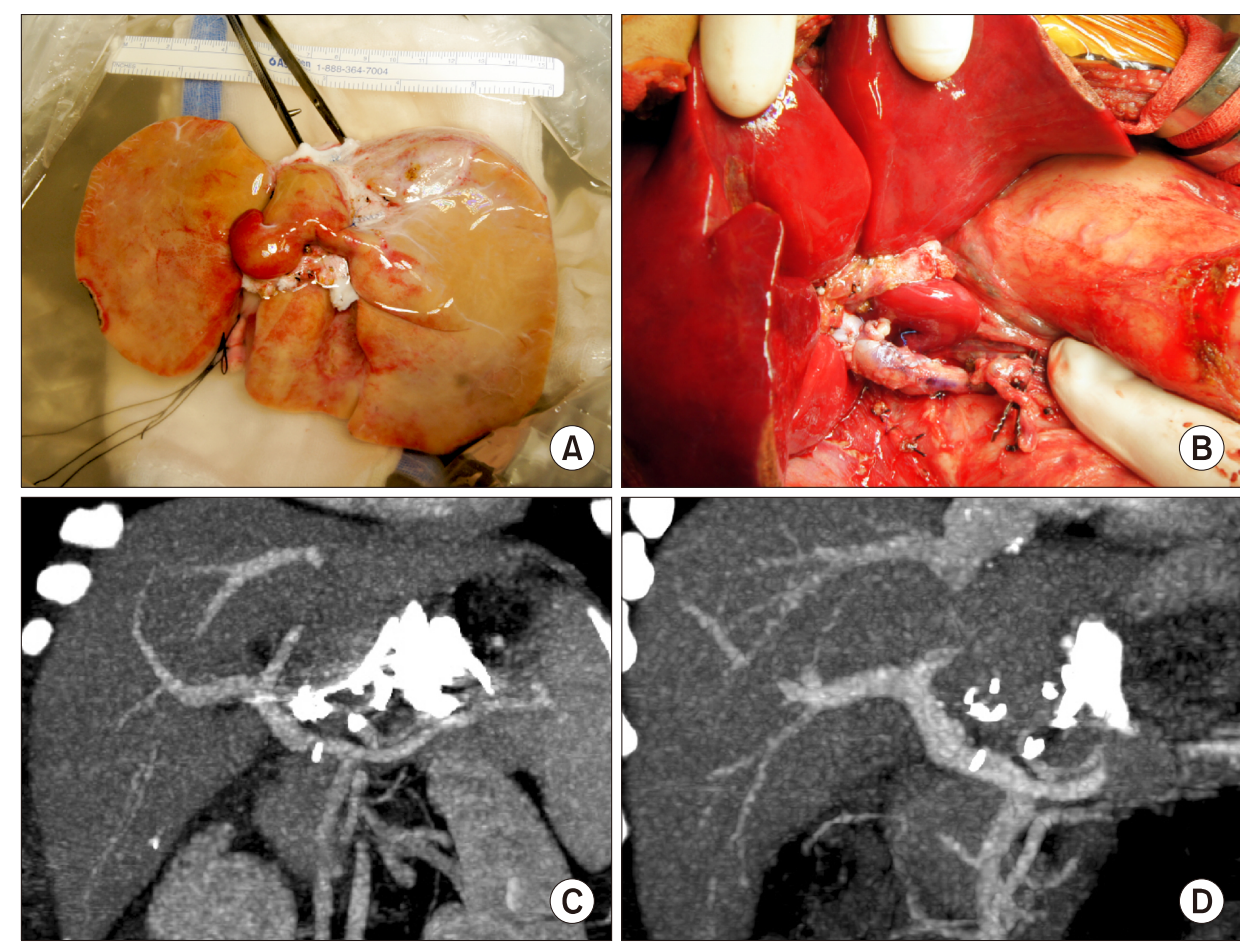

Fig. 3. Imaging findings of PV reconstruction using the side-toside unification technique in Case 2. The ventral surface of the whole liver graft was visible with closure of the inferior stump of the vena cava (A). Redundant PV reconstruction with side-to-side unification technique was shown to avoid compression by the caudate lobe (B). Dynamic computed tomography scans were taken at posttransplant 5 days $(\mathrm{C})$ and 1 year (D), showing no evidence of PV complication. anastomosis. Because the graft liver was much larger than the native liver, we designed the length of the extrahepatic PV more redundant than the precedent cases to avoid extrinsic compression by the large caudate lobe. The PV was reconstructed using side-to-side unification venoplasty (Fig. 3, Supplementary Video 3). One hepatic artery was reconstructed under surgical microscopy. Roux-en-Y hepaticojejunostomy was performed. The function of the graft liver recovered uneventfully. There was no evidence of PV complications. She is currently doing well for 2 years.

\section{DISCUSSION}

For I2I-WLT, the most important factors for success of LT are the graft-recipient size matching and PV reconstruction. It is difficult to determine whether the liver graft is well matched with the infant recipient, but general insights can be learned from high-volume center experiences with pediatric LDLT. For PV reconstruction in I2I-WLT, infant recipients with biliary atresia often exhibit overt PV hypoplasia and underdevelopment of the splanchnic blood flow system, so secure PV reconstruction is a major matter of concern. ${ }^{1,3,5,6}$

To secure PV reconstruction in I2I-WLT, we developed a new surgical technique that would be suitable for
I2I-WLT, which we termed the side-to-side unification technique. At the recipient-side SMV-SV confluence, this technique is very similar to that of the tadpole-shaped PV anastomosis procedure described above. At the graft-side hilar PV, it is also similar to the use of a conventional patch venoplasty to enlarge the PV diameter. Follow-up imaging studies revealed that the shape of the PV after application of side-to-side unification technique had a wide patch-expansion effect at both the SMV-SV and hilar PV confluences. This expansion effect made the shape of the reconstructed PV smooth and streamlined, which is well matched with the hemodynamic principles.

For infant LT recipients, PV stenting should be avoided because it can cause late-onset portal insufficiency that leads to inevitable need for retransplantation. Secure PV reconstruction should be a high priority so that PV stenting can be avoided, which is quite different from adult LT cases because PV stenting in infants cannot be sufficiently enlarged, although there is some enlargement of the PV stent. ${ }^{7,8}$ Finally, PV stenting induces overt PV stenosis when the infant recipients grow up. Indeed, the long-term outcome of percutaneous transhepatic balloon angioplasty is often reported to be favorable in cases of pediatric LDLT. ${ }^{9}$

In conclusion, we present a side-to-side unification tech- 
nique for PV reconstruction that is reliably applicable to I2I-WLT. We propose that this technique may represent a useful surgical option for PV reconstruction in pediatric LT.

\section{SUPPLEMENTARY DATA}

Supplementary data related to this article can be found at https://doi.org/10.14701/ahbps.2020.24.3.301.

\section{ORCID}

Jung-Man Namgoong:

https://orcid.org/0000-0002-9237-7440

Shin Hwang: https://orcid.org/0000-0002-9045-2531

Chul-Soo Ahn: https://orcid.org/0000-0002-3844-3646

Dong-Hwan Jung:

https://orcid.org/0000-0001-5984-023X

Gil-Chun Park: https://orcid.org/0000-0003-1631-3258

\section{REFERENCES}

1. Hwang S, Kim DY, Ahn CS, Moon DB, Kim KM, Park GC, et al. Computational simulation-based vessel interposition reconstruction technique for portal vein hypoplasia in pediatric liv- er transplantation. Transplant Proc 2013;45:255-258.

2. Mitchell A, John PR, Mayer DA, Mirza DF, Buckels JA, De Ville De Goyet J. Improved technique of portal vein reconstruction in pediatric liver transplant recipients with portal vein hypoplasia. Transplantation 2002;73:1244-1247.

3. Takahashi Y, Nishimoto Y, Matsuura T, Hayashida M, Tajiri T, Soejima Y, et al. Surgical complications after living donor liver transplantation in patients with biliary atresia: a relatively high incidence of portal vein complications. Pediatr Surg Int 2009;25: 745-751.

4. Ueda M, Egawa H, Ogawa K, Uryuhara K, Fujimoto Y, Kasahara $\mathrm{M}$, et al. Portal vein complications in the long-term course after pediatric living donor liver transplantation. Transplant Proc 2005; 37:1138-1140.

5. Kasahara M, Umeshita K, Sakamoto S, Fukuda A, Furukawa H, Uemoto S. Liver transplantation for biliary atresia: a systematic review. Pediatr Surg Int 2017;33:1289-1295.

6. Gu LH, Fang H, Li FH, Zhang SJ, Han LZ, Li QG. Preoperative hepatic hemodynamics in the prediction of early portal vein thrombosis after liver transplantation in pediatric patients with biliary atresia. Hepatobiliary Pancreat Dis Int 2015;14:380-385.

7. Yeh YT, Chen CY, Tseng HS, Wang HK, Tsai HL, Lin NC, et al. Enlarging vascular stents after pediatric liver transplantation. J Pediatr Surg 2017;52:1934-1939.

8. Ko GY, Sung KB, Lee S, Yoon HK, Kim KR, Kim KM, et al. Stent placement for the treatment of portal vein stenosis or occlusion in pediatric liver transplant recipients. J Vasc Interv Radiol 2007;18:1215-1221.

9. Yabuta M, Shibata T, Shibata T, Shinozuka K, Isoda H, Okamoto $\mathrm{S}$, et al. Long-term outcome of percutaneous transhepatic balloon angioplasty for portal vein stenosis after pediatric living donor liver transplantation: a single institute's experience. J Vasc Interv Radiol 2014;25:1406-1412. 